\title{
Panel Commentary: Clinical and Training and Knowledge Exchange Implications
}

\section{Brian Rush}

Published online: 22 December 2007

(C) Springer Science + Business Media, LLC 2007

\section{Afternoon of Day Two}

\section{Linda Sibley}

Executive Director

Thames Valley Addiction Services

Suite 200 - 256 Pall Mall Street

London, Ontario N6A 5P6

\section{Christine Bois}

Priority Coordinator, Concurrent Disorders

Centre for Addiction and Mental Health

33 Russell Street

Toronto, Ontario

M5S 2S1

\section{David Ross}

Coordinator of Professional Services

Pavillon Foster

3285, boulevard Cavendish,

Montréal, Québec

H4B 2L9

\section{Dale Butterill}

Manager, Knowledge Transfer

Centre for Addiction and Mental Health

33 Russell Street

Toronto, Ontario

M5S 2S1

The online version of the original article can be found at http://dx.doi.org/10.1007/s11469-007-9105-5.

B. Rush $(\bowtie)$

Health Systems Research and Consulting Unit, Centre for Addiction and Mental Health, Toronto, Canada e-mail: Brian_Rush@camh.net 
The incorrect version of this article was published. Below please find the correct version.

\section{Panel Discussion (2nd afternoon)}

\section{Linda Sibley}

Linda Sibley: We have covered a tremendous amount of ground over two days and a lot has been said. Christine and I are going to speak on implications with clinical practice and training and I would start by commenting on the diagnostic versus dimensional distinction. Although the discussions are very interesting there is a place for both in our clinical world. We also really need to do things with a broad brush; we need to try new things, and we need to have pilot studies that we can evaluate. Sometimes perfection is the enemy of good enough, and we can learn a lot by trying things in a safe way because I think we also need to abide by the comment that Dr. Parikh made about doing no harm. Obviously that drives us, and that has to be the underpinning of whatever we try to do. When we do pilot studies I think we need to "work with the willing"; we need to go to our business relationships, go to people who are usually willing to try to implement new processes because it is a tremendous amount of work in very busy schedules to try new screening tools and outcome measures, and track something differently. It takes a fair amount of preparation and, while it might feel obvious to work with the willing, I really think we need to remind ourselves of that all the time.

Another point is to use a broad brush, going back to Marilyn's point this morning about self-administered tools through the Internet. I think there is a really good opportunity here. I think there are many people in the community who can successfully a website. You know we have website contact probably in every one of our programs, at least one or two a week. People are negotiating their way through the health system. There is tele-health, and telepsychiatry all kinds of ways consumers are getting; information even just as a place to start. I do think we need to try everything.

Going back to the discussion this morning about the four quadrants, I think there will always be really diverse opinions and philosophies, and that it is really important to accept that there are probably different kinds of screening instruments and tools that will really work in each of the different quadrants. In Ontario, we have a real acceptance of harm reduction as a legitimate strategy and treatment intervention, and so anything that we embrace as a province needs to work in that context. So it needs to be a tool that can be adapted to the environments that we work in.

New screening tools alter the process of your program. So even as one of the early converts for the Ontario standardized assessment tool initiative, one of the things that happened within my own local treatment system and our agency concerned the way that we deliver our programs. Because we had new tools a lot of things changed to the process that clients follow from the front door in the waiting room through into the back of the agency to the clinical offices. Some tools did lend themselves to the group interview process. Most of our intake is done in groups of 6-8 and we book 10-12 knowing that there will be about a $60 \%$ show rate. So we do play those odds. In our group intake session several of the tools that lend themselves to this are administered to those people at once and many agencies now do that as well. It really does work, as an efficient intake system. So when you bring new things in like a mental health screener, at what point would we administer that and what will it do to the other people in the group, for example. Initially we used all the tools in the group and we found it didn't work. So we actually changed our program, the process of how the clients move through into our internal decision tree, if you will. We changed it probably two or three times to make it fit. So I think that is part and parcel of some of the implementation issues that come up and, even 
with a very willing group of volunteers to try something, it really takes a lot of work at the other end to make it work. I'll hand things over to Christine.

\section{Panel Discussion (2nd afternoon)}

\section{Christine Bois}

Christine Bois: I'll be talking about future implications for clinical work and training. We all start in university and when we are in university we, and the people who are training us, assume we are all learning what we need to know to do our job. We also know, however, what happens then is we take the knowledge and we go out and use it for 20 years, and we don't change it for those 20 years because we learned it that way. Unfortunately we know that doesn't work and I think it would really be useful as a starting process if our education system, when you hit graduate and post graduate level, helped us understand that we are not really learning very much. What we are really learning is how to think; how to evaluate; how to know what is good research; how to know what might be useful; how to know what is ethical; how to know what is a useful piece of research to people. They should be teaching us that our education is an ongoing and changing process and that probably our best teacher would be the clients who come to us for help. If we had an education system that supported that then the future generations wouldn't be so entrenched in not wanting to change the way they are doing business now.

The other assumption that we have made, and I know I've made it and I think it is wrong, is that training is a tool to create change in how people do their work. I don't think it is effective. Let's say we are going to teach you how to use this screening tool and we are going to give you two days training in a didactic manner, then goodbye; you've learned it; go do it. It is not effective because, as one person has said this morning, we haven't engaged them in how to actually do the screening. We also don't follow up and we don't provide them with any support. I mean support in terms of clinical supervision in how to do it with the clients that need more help, or may in fact be challenging us on the use of the screening tools. Not only do we need ongoing supervision to work with these tools as a part of the training strategy, I think we also need to involve the administrators, the managers, and the clinical supervisors around the implementation in their agency, and how to help their staff use the tools. They also need support in how to use these tools in an effective way in sharing the information with other agencies in their addiction or mental health system or across those systems. Too often we leave out the provider, the administrator or the supervisor.

I would also like to comment on what Linda talked about as her group intake process. I think she was one of the first people in the province to do it, and it didn't take very long until other agencies meeting at the Director level heard that Linda instituted a group intake process and so they went and asked her how is it working; send me your information; and help me understand what you are doing. Many other agencies subsequently started to deal with five-month waiting lists by then instituting the process of a group intake. Also, as Wayne said this morning, when we started talking about instituting smoking cessation in treatment programs we initially believed that was the wrong thing to do until we discovered it wasn't. So I think many agencies were saying each client has to been seen individually at screening and intake, and in fact Linda changed the process for many agencies by giving it a try. I think it would be really useful if funders/planners could give a little extra money to some of these agencies who want to try doing something differently; that they want to institute a new process; and that encourages and supports the agencies to be able to do it, and then they have an opportunity to share it with their peers as well. 


\section{Panel Discussion (2nd afternoon)}

\section{David Ross}

David Ross: I work with a service provider called Pavillon Foster. It is an organization situated in Montreal and immediate regions but we have a larger regional mandate. Our responsibility is to deliver treatment to anyone in Quebec who wants it in the English language. Recently I have been closely involved in knowledge transfer and how to apply and develop best practices for our system. About three years ago I was asked to chair a committee, the purpose being to figure how best to manage concurrent disorders. There had been two previous committees which had put out two reports, but nothing much changed in terms of clinical practices. So what happened?

We did what we could to establish why the impact of the previous reports had been as limited as it was. The first thing we did was to review the literature and check the recommendations against the best practices at that time, and they looked like there was a good correspondence. So that wasn't the obvious reason why things hadn't changed much. So the next thing I did was to go around and talk to people at the various centers. My original bias was that "these people don't think this is an important issue and they really don't care", but this was absolutely not the issue. There were some interesting reasons why things hadn't changed much. One was the marked heterogeneity of the models used for assessment and treatment. The treatment centers had grown up organically in regions without a common framework defining best practices in terms of service delivery, hence there was no common language, no common model for assessment, and huge differences in organizational cultures. So there was significant variation in their perceptions of what was needed. In terms of professional training they went from people who had absolutely none, and who had been grandfathered in, to the average person who is an A.R.H (Agent des Relations Humaines), a clinical position defined by the Ministry of Health, which usually means that they have a B.A. in arts degree or B.Ed. There were very few psychologists at that time. So there was a lot of variability in their ability to know what they didn't know. We did a survey of the treatment centers in the province and we asked them how many knew how to screen for various conditions. We got a response indicating that between $1 / 3$ and $2 / 3$ said "yes we can do it". However, we then asked them how they arrived at this conclusion by asking "What instruments are you using for screening"? These people were saying they were screening for concurrent disorders using DAST or ADS, or other instruments that, if they are doing it, I don't know how. There was a lot of variability in the perception of responsibilities and natural core competencies. So this contributed to the inconsistency. There were also some pan-systemic factors. For example, there was limited support in terms of government funding for existing programming; this is an issue in Quebec, as many feel that we don't have enough money to treat people with alcohol and other drug problems already. So the response was "What, more responsibilities!" The next issue was a general lack of vision, extrinsic motivation and resource allocation from oversight bodies. To be polite, I'm not sure if the government knows exactly what to do with us because they are not quite sure who should be responsible for this issue. Thus, they are not clear in the messages that they send to the centers as to whether the centers are responsible for dealing with concurrent disorders or not. So if there is no clear message and it's not a delegated responsibility, then you are probably not going to go very far. So that was a part of the issue. Another thing is that there is not a lot of support for sustained retraining. Given what I mentioned about the variable professional qualifications of the staff, you know when you go to actually transferring this knowledge you can forget about 
the "B52" approach to training where you come in "drop your bombs" and keep on moving. You have to sustain your training over an extended period of time. They also have to know you are coming back, and it should be every two weeks to a month because, if it's beyond that, you have to start over and it gets very expensive. Finally, there were issues of systemic readiness. Issues like impending change of government; that's always a good one because everybody freezes in their seats. Competition for existing funding is another factor. The next thing you become aware of is the "Sure, change is great - why don't you go first" phenomenon, which I sympathize with since we have until relatively recently lacked explicit models for how to go about actually making the changes. Unfortunately in some cases this is an after-thought, but it really shouldn't be because this is a major issue in terms of the difference between your programming actually still sitting on the shelf or actually making it into implementation. At the time there was a weak evidence base, particularly in Quebec. There had been a lot of research done on transfer knowledge but none of it had been transferred into the Quebec addictions area. So nobody quite knew how to go about trying to make big systemic changes and they weren't sure about what steps they should be following. So in terms of screening they are faced with the big unknown. Sure I can screen but what is going to happen next? What am I going to do now? This can be quite daunting to an individual clinician, and the more that clinician is operating in a disintegrated system in a remote setting with minimal support, the less likely they are to engage themselves in the process. So the contingencies were unclear or unfavorable in terms of the "risks to gain ratio" for the people that were actually supposed to be doing it. Another point is that there was a lot of good people who felt very bad about the situation and wanted to do things. However, if you start making changes in your service delivery system, and you do it in isolation, whether you are an individual clinician or an individual organization, and there is no message about "yes, you should be trying this!" or "yes, it's okay to pilot!", and "yes, its okay to fail!", it is a very risky situation for you. In the end, I think there were some contingencies that were actually preventing people from even experimenting with it.

Finally, there is my personal favorite that "it is irresponsible to detect if you can't then intervene argument". This is admittedly a thorny issue and we have already had some discussion on this one. I have to tell you that my clinical experience so far, even when we detect and can not intervene with a chronic condition such as PTSD, we have found it somewhat preferable to at least sit with the client and say "yes we know we can't provide all the services you may need, but on the other hand, this is really a personal issue; it is not character defect but rather a condition with a diagnosis and there are treatment options. Although these options may be hard to attain, we are not going to blow you off and we are not going to ignore you, and we are not going to tell you that you are not a good patient because you can't manage the group work due to your symptoms. In other words, there is not a lot we can do beyond basic psychoeducation, but we have seen in our centre that this basic step can facilitate retention and relieve client burden in some cases that are perhaps not trivial accomplishments.

\section{Panel Discussion (2nd afternoon)}

\section{Dale Butterill}

Dale Butterill: The big challenge of having anything to say at this point in a two day meeting is to say anything that is new. I was going to talk about what we have on the ground in Ontario and what we would like to see happen as a result of our screening and assessment process, and then to present you with a nice little framework on how these 
things get implemented based on stages of change, and who the main players are. However that is a little too comfortable. There is so much collective wisdom and knowledge in this room, and there has been so much talk over the last two days about all of these things, that I don't need to repeat it. So the challenge is whether I have anything to add to this mix, and you will have to be the judge of that.

Everyone in this room is a change agent. Everyone has been trying to change screening processes, clinical processes, programs, behaviors and even intervene at the systems level. In this province, and as I learn from our colleagues from other areas of the county and from the United States, we have been spectacularly unsuccessful at large scale systems change. We have sterling examples of programs on the ground where programs are sharing resources and where individuals have taken leadership within a network or within a region to develop planning processes and evaluation processes. That said, a client in our system here in Ontario has no reasonable expectation for standard of care across the province. So if they happen to have the good fortune to live now up in Parry Sound and have a concurrent disorder they have a program to go to but you can't say that across the board. We are change agents but what do we need to add to our change agent thinking in order to be more effective at the systems level. Also I think there is something quite fundamental about this and I think part of it is taking a leap of faith and trusting our tools; trusting our leadership; trusting our processes; and trusting our commitment and moving forward on that basis. I think what we have done over the last couple of days is really interesting and very stimulating intellectually. However, we are extremely accepting and extremely understanding of why the system is the way it is; for example, why we have a parallel mental health and addictions systems. Why do programs have difficulty accepting evidence-based recommendations for change in practice? We are very, very tolerant and I'm suggesting that we be a little less tolerant and that people in this room are the change agents for a population we all care about. So I think we need to renew our sense of urgency and our passion around this and go forward. I also think we need to make our priority the systems priority. I think we need to find the common ground and stop talking about the differences and I think we need to renew our commitment to the people who need our services, clients and the families in our systems and put them first and foremost. We need to put ourselves in their shoes trying to navigate this system and trying to listen to our intellectual rationale and understanding of why things are the way they are, and why we can't do better and make a difference.

\section{Audience Discussion}

\section{Afternoon of Day Two}

Cynthia Zupriski We have done a lot of work with telephone disease management, telephone screening and assessment and video screening and assessment. When we started this, people said it wouldn't work; that you have to look people in the eye, and I agree that is the best way to do things. However, we have had lots and lots of success using telephone disease management and if you can afford video cams, then that is great and might be something that you can look into.

Greg Greaves I just wanted to make a brief point about capacity to create a continuum in screening and assessment between mental health and addictions. Our organization just completed a major survey called Optimizing Canada's Addiction Workforce. We went out 
and surveyed 200 treatment directors and agency heads, and 200 front line staff and there is some fascinating analysis from that survey. One point that is very relevant to us is that we presented about 36 professional development options that would be of interest to front line staff and concurrent disorders came out number one out of 36.

Steve Lurie I was just thinking about the whole two days in relation to the initiative that is rolling out in Ontario, that is the mental health and justice initiative. I think that what we are going to face is police bringing people to safe houses, to pre-charged diversion. We have got a volume of 1800 people at court support programs now where $2 \%$ of them are getting the kind of services they need based on the Colorado Client Assessment Record that was administered in a research capacity a couple of years ago. So I think for the mental health and justice sector this is starting to come together and most of the services are going to be provided in the community mental health sector. People need tools to both manage risk, and to assess risk in a timely manner you don't have time to put people on waiting lists. If they show up in a safe bed, or a decision is pending regarding jail, you are going to want to know what the risks are that you will be asked to manage. You can't say, well we are going to do a screening and then we are going to do an assessment three weeks later because you are in the bed now. So it seems to me some of this is actually about helping people in the system assess risk and the other part is helping them with care planning.

Unidentified Participant I meant to say this earlier and I'd like to really support David in your position. I would come on the side that it is responsible to screen even if you can't yourself immediately respond to the need that emerges. In fact I think it is unethical to not do that. I think the responsibility is that, if you can't do it, then you find a partner who can. I know it can be done in the States and I don't know any reason why it couldn't be done up here. It may take some time to implement but to leave part of a problem unaddressed is a guaranteed way to set the person up for a relapse on both sides of the coin, both substance abuse and mental health.

David Ross I just finished a three-day conference in Quebec where we reviewed our stance on concurrent disorders and three years ago the Federation was very reluctant to deal with the issue. The Federation just adopted a resolution for its plan for the next ten years to do everything it can to require each treatment centre to assure the continuity of care for every client with a concurrent disorder. It is a big change for the Federation because before it was like "I don't want to look at it anymore". Now people aren't sure what to do with it. We absolutely don't have all the answers and the same issues are still issues but there has been a change in the willingness of the average clinician in the treatment centre to assume responsibility to either intervene or to accompany the client actively to the referral source as opposed to saying get out of my face, you go there. So I think there are grounds for cautious optimism. 